\title{
Topical corticosteroid abuse among pediatric population - a prospective study
}

\section{Mrinal Gupta}

\author{
Department of Dermatology, Treatwell Skin Centre, Jammu and Kashmir, India
}

Corresponding author: Dr. Mrinal Gupta, E-mail: drmrinalgupta@yahoo.com

Sir,

Topical corticosteroids (TCs) are one of the most commonly used preparations in dermatology practice. Their rapid anti-inflammatory, immunosuppressive and anti-pruritic activity has made them the drug of choice for a large number of dermatoses [1]. Apart from the well documented uses of TCs, they can also cause a wide array of adverse effects if used indiscriminately or for long duration without supervision which include steroid rosacea, acneiform eruption, hypertrichosis [2]. TCs misuse is a common problem in our country owing to their easy availability as over the counter medication and preparations and lack of awareness among the general population. TCs are commonly being used as fairness and anti acne medications by the general population without any dermatological consultation which has led to a significant number of patients presenting with cutaneous adverse effects of TCs to the dermatologists [2,3]. Corticosteroid abuse is also being observed in pediatric population where topical steroids are being misused by the caregivers either as self-medication or by using them for duration more that that advised by a dermatologist.

This study was carried out in a dermatology outpatient centre with the main aims of studying the clinicepidemiological features of TCs misuse among the pediatric population.

This was a prospective, questionnaire based study carried out over a period of one and half year in our centre in which the patients were questioned and assessed for misuse of TCs in terms of indication, frequency, duration and source of recommendation. All the patients who had been self-medicated with TCs or where the parents/caregivers had used TCs beyond the prescribed time advised by the dermatologists were included in the study. After taking an informed consent, the patients were assessed regarding the formulation, frequency, duration or indications of TCs use for different skin conditions and the various cutaneous adverse effects, wherever present, were also noted.

A total of 50 patients (M: F 29:21) were included in our study. The age range of patients varied from 6 months to 18 years with a mean age of 11.35 years. Most of the patients were aged $>12$ years $(54 \%)$. The age distribution and the indications for steroid use are enumerated in Table 1. The most common indication for TCs use in our study was eczemas (32\%), fungal infections (20\%), bacterial and viral infections (18\%), acne (12\%) and facial pigmentation (10\%). The most commonly abused corticosteroids were mometasone (36\%), clobetasol (26\%) and betamethasone (22\%) (Table 2). The duration of TCs use varied from three days to one year in our study group whereas the frequency of use varied from thrice a week to thrice a day. Mometasone based Kligman's combination and salicyclic acid-clobetasol combinations were also being used over the face in pediatric population for indications like acne and acne scarring.

The lack of awareness among the population can be gauged from the fact that only $18 \%$ patients $(n=9)$ were aware of the adverse effects of TCs misuse. A large majority of patients $(32 \%, \mathrm{n}=16)$ were using topical corticosteroids on advice of friends or relatives, 28\% $(n=14)$ on the advice of pharmacists or paramedical personnel; 6 (12\%) patients were using them based on information from internet or other sources, 4 (8\%) were advised by beauty parlors and beauticians. Ten patients $(20 \%)$ were using the TCs advised by the dermatologists, but had been using them for a period beyond the advised time frame or had been using it 
Table 1: The various indications for topical corticosteroid use among study population

\begin{tabular}{lcc}
\hline Indications for TCs use & $\begin{array}{c}\text { Age }<\text { 12 years } \\
(\%)\end{array}$ & $\begin{array}{c}\text { Age 12-18 years } \\
(\%)\end{array}$ \\
\hline Eczemas & $10(20)$ & $6(12)$ \\
Fungal infections & $4(8)$ & $6(12)$ \\
Bacterial and viral infections & $5(10)$ & $4(8)$ \\
Acne & $1(2)$ & $5(10)$ \\
Pigmentation & 0 & $5(10)$ \\
Others & $3(6)$ & $1(2)$ \\
Total & 23 & 27 \\
\hline
\end{tabular}

TCs: Topical corticosteroids

Table 2: Nature of corticosteroids used in the study population.

\begin{tabular}{lcc}
\hline $\begin{array}{l}\text { Type of TCs } \\
\text { use }\end{array}$ & $\begin{array}{c}\text { Age }<\mathbf{1 2} \text { years } \\
(\%)\end{array}$ & $\begin{array}{c}\text { Age 12-18 years } \\
(\%)\end{array}$ \\
\hline Mometasone & $6(12)$ & $12(24)$ \\
Clobetasol & $4(8)$ & $9(18)$ \\
Betamethasone & $7(14)$ & $4(8)$ \\
Beclomethasone & $2(4)$ & $1(2)$ \\
Fluocinolone & $1(2)$ & $1(2)$ \\
Clobetasone & $2(4)$ & 0 \\
Desonide & $1(2)$ & 0 \\
Total & 23 & 27 \\
\hline
\end{tabular}

TCs: Topical corticosteroids

for some other indication. None of the patients had information regarding the potency of different steroids or the ideal quantity of TCs to be used or the concept of finger tip units.

Cutaneous adverse effects were seen in $16 \%$ patients with the most common adverse effects being tinea incognito $(6 \%)$, steroid acne (4\%), dyspigmentation (2\%), hypertrichosis $(2 \%)$ and striae $(2 \%)$.

The dermatological therapy underwent a sea change with the introduction of Hydrocortisone in 1952, which was followed by the development of a large variety of more potent topical corticosteroids. Owing to their potent antiinflammatory, anti-proliferative, immunosuppressive, anti-pruritic and atrophogenic effect on the skin, TCs have become the most commonly used drug for various hyperproliferative, inflammatory, and immunologic disorders of the skin [1]. But these properties of TCs have proven to be a double-edged sword as they provide rapid symptomatic relief in a large number of dermatoses, owing to which, they are commonly being sold overthe-counter and used by the patients irrespective of the underlying disease. Surprisingly, they are commonly being used as anti-acne and fairness creams by a large number of young patients. Their low cost and easily availability has added to the growing menace [2,3].

The problem of TCs abuse has been widely reported from all over the developing world. A study from Iraq reported that $7.9 \%$ of out patient attendees in dermatology clinic had misused TCs [4]. In a similar study by Saraswat et al in India, 433 patients misusing TCs were studied. It was observed that the majority were females $(n=321)$ and the most common age group was $21-30$ years (36\%), and the most common age group was $20-40$ years $(56 \%)$ [5]. Not much data is available regarding the TCs abuse in the pediatric population, so we undertook this study to assess the prevalence and patterns of misuse of TCs among children by their caregivers.

The most common indication for TCs use in our study was eczemas (32\%), fungal infections (20\%), bacterial and viral infections (18\%), acne (12\%) and facial pigmentation (10\%) and surprisingly, TCs are the not the treatment of choice for most of these dermatoses. \%). The most commonly abused corticosteroids were mometasone (36\%), clobetasol (26\%) and betamethasone (22\%). A significant number of patients $(26 \%, n=13)$ were using the irrational overthe-counter three or four drug combinations which include a corticosteroid, an antibiotic and an antifungal. The use of mometasone based Kligman's formulation and potents steroid like clobetasol with a combination of salicyclic acid over the face in pediatric population without any dermatologist supervision is alarming. This aspect can be attributed to the lack of awareness among the general population towards the use of TCs.

The inappropriate use of TCs can lead to multiple side effects including atrophy, striae, telengiectasis, purpura, hypopigmentation, acneiform eruptions, rosacea-like perioral and periorbital dermatitis and hypertrichosis $[5,6]$. Cutaneous adverse effects were seen in $16 \%$ patients with the most common cutaneous adverse effects being tinea incognito (6\%), steroid acne (4\%), dyspigmentation (2\%), hypertrichosis $(2 \%)$ and striae $(2 \%)$.

Our study had several limitations. The small number of study population and the study being limited to the OPD of a single centre doesn't characterize the whole population in general.

The study reveals the rampant problem of TCs abuse in our setup and the abuse of TCs in pediatric population is disturbing. The general public and the health care providers at the peripheral levels need to be made aware of the serious adverse effects of inappropriate TCs use and a strict regulation should be brought to control the unauthorized sale of TCs as over the counter preparations without proper prescription by the doctor. 


\section{Statement of Human and Animal Rights}

All procedures followed were in accordance with the ethical standards of the responsible committee on human experimentation (institutional and national) and with the Helsinki Declaration of 1975, as revised in 2008.

\section{Statement of Informed Consent}

Informed consent was obtained from all patients for being included in the study.

\section{REFERENCES}

1. Becker DE. Basic and clinical pharmacology of glucocorticosteroids. Anesth Prog. 2013;60:25-31.
2. Dey VK. Misuse of topical corticosteroids: A clinical study of adverse effects. Indian Dermatol Online J. 2014;5:436-40.

3. Jha AK, Sinha R, Prasad S. Misuse of topical corticosteroids on the face: A cross-sectional study among dermatology outpatients. Indian Dermatol Online J. 2016;7:259-63.

4. Al-Dhalimi MA, Aljawahiri N. Misuse of topical corticosteroids: A clinical study from an Iraqi hospital. East Mediterr Health J. 2006;12:847-52.

5. Saraswat A, Lahiri K, Chatterjee M, Barua S, Coondoo A, Mittal A, et al. Topical corticosteroid abuse on the face: A prospective, multicenter study of dermatology outpatients. Indian J Dermatol Venereol Leprol. 2011;77:160-6.

6. Hengge UR, Ruzicka T, Schwartz RA, Cork MJ. Adverse effects of topical glucocorticosteroids. J Am Acad Dermatol. 2006;54:1-15.

Copyright by Mrinal Gupta. This is an open-access article distributed under the terms of the Creative Commons Attribution License, which permits unrestricted use, distribution, and reproduction in any medium, provided the original author and source are credited.

Source of Support: Nil, Conflict of Interest: None declared. 